\title{
PIBID INGLÊS UFES: CONSTITUIÇÃO IDENTITÁRIA E CONFLITO EPISTEMOLÓGICO ENTRE A UNIVERSIDADE E A ESCOLA PÚBLICA
}

Luciana Ferrari ${ }^{1}$

Lívia Fortes ${ }^{2}$

Resumo: Este artigo tem como objetivo discutir a formação de professores de inglês a partir das experiências do Pibid Inglês da Ufes nos anos de 2018-2019. Visando encurtar as distâncias entre a escola pública e a formação superior no âmbito das licenciaturas, o Pibid (Programa Institucional de Bolsas de Iniciação à Docência) tem se constituído enquanto espaço de aprendizagens múltiplas e, decerto, relevantes para a formação docente. Nos âmbitos da formação inicial e continuada, não há como negar sua importância na constituição identitária e profissional dos graduandos, dos supervisores (docentes das escolas), bem como das coordenadoras (docentes na Universidade que aqui escrevem). Entretanto, como qualquer processo subjetivo e formador, a experiência educativa em voga também pode ser compreendida como arena de conflitos e resistência se pensamos na pluralidade dos sujeitos e dos saberes que se interconectam pelas teias de sentidos e vivências que ali se dão. Os dados a serem debatidos e interpretados nesta discussão são de natureza qualitativa e originaram-se da escrita de diários de campo por parte dos bolsistas graduandos, bem como de observações feitas a partir de interações entre coordenadoras e supervisores. Debateremos, portanto, com maior ênfase, a natureza dos conflitos epistemológicos que emergiram nessa dinâmica, a influência dos mesmos na constituição identitária dos bolsistas graduandos, a dificuldade de ruptura com modelos tradicionais e práticas concebidas à sombra da Modernidade, finalizando com reflexões sobre emancipação e educação subjetificadora.

Palavras-Chave: Pibid. Identidade. Epistemologias. Emancipação. Educação Crítica de Línguas.

Abstract: This article aims to discuss English teacher education from the experiences of the English Pibid at Ufes in the years 2018-2019. In order to shorten the distance between the public basic school system and higher education in the context of undergraduate courses in Brazil, the Program Pibid (Institutional Program for Teaching Initiation Scholarships) has constituted itself as a space for multiple learning and, certainly, relevant to teacher education experiences. In the areas of pre-service and in-service education, its importance in the identity and professional constitution of undergraduates, supervisors (school teachers), as well as the coordinators (teachers at the University who write here) cannot be denied. However, like any subjective and formative process, the present educational experience to be discussed heretofore can also be understood as an arena of conflicts and resistance if we think of the plurality of subjects and knowledge that are interconnected through the webs of meanings and experiences that take place there. The data to be debated and interpreted in this discussion are of a qualitative nature

\footnotetext{
${ }^{1}$ Departamento de Línguas e Letras da Universidade Federal do Espírito Santo. Email:luferrarioliveira2019@gmail.com

${ }^{2}$ Departamento de Línguas e Letras da Universidade Federal do Espírito Santo. E-mail: lifortes34@gmail.com
} 
and originated from the journals written by the undergraduate scholarship holders, as well as the perceptions drawn from the interactions between coordinators and supervisors. We will therefore debate, with greater emphasis, the nature of the epistemological conflicts that emerged in this dynamic, their influence on the undergraduates' identities, the difficulty of breaking with traditional models and practices conceived under the shadow of Modernity, ending with reflections on emancipation and subjectifying education practices.

Key-words: Pibid. Identity. Epistemologies. Emancipation. Critical Language Education.

\section{Conflitos epistemológicos, formação identitária e o Pibid Inglês da Ufes}

Sabemos o quanto a Universidade e a Licenciatura têm lutado para encurtar as distâncias entre o mundo acadêmico e a educação básica e, assim, desconstruir o mito acerca de que teoria e prática ocupam lugares distintos na formação docente e, mais ainda, na constituição de tecidos sociais. Nesse cenário, o Pibid, como política de governo instituída em 2008, durante o segundo mandato do Presidente Lula, e hoje em sua quinta versão na Ufes (Universidade Federal do Espírito Santo), tem se constituído enquanto espaço de formação profissional e, consequentemente, constituição identitária de futuros educadores do ensino básico por meio de vivências e trocas de saberes entre alunos graduandos e o universo escolar. E nessa dinâmica, a Licenciatura e seus docentes também se veem em processo de formação continuada e passam a ter novas oportunidades de refletir sobre suas práticas, epistemologias e seu papel social, ou seja, suas identidades, tendo em vista que os sujeitos envolvidos vivenciam experiências situadas no chão da escola e as trazem para a sala de aula da Universidade, denunciando por vezes o alinhamento das práticas e discursos nos contextos em voga, bem como possíveis desalinhos e conflitos a serem encarados pelos sujeitos e instâncias envolvidos no processo educativo. Identidades em (trans)formação como qualquer processo educacional e, portanto, dialógico, deve prever.

Entendemos, portanto, que o Pibid Inglês Ufes, por nós coordenado entre 2018-2019, alcançou os seus objetivos, muito embora tenhamos críticas aos mesmos quando se pontua, conforme se lê abaixo, que a qualidade da formação inicial deve ser "elevada". Acreditamos que o Pibid seja uma excelente oportunidade de diálogo, trocas e ressignificações acerca da sala de aula e do profissional de ensino de língua inglesa (LI), o que não implica, necessariamente, no entendimento de que a formação que praticamos sem o Pibid não seja uma formação de qualidade. Ainda assim, listamos abaixo os objetivos do programa a título de esclarecimento: 
1. contribuir para a valorização do magistério;

2. elevar a qualidade da formação inicial de professores nos cursos de licenciatura, promovendo a integração entre a Educação Superior e a Educação Básica;

3. inserir os licenciandos no cotidiano de escolas da rede pública de educação, proporcionando-lhes oportunidades de criação e participação em experiências metodológicas, tecnológicas e práticas docentes de caráter inovador e interdisciplinar que busquem a superação de problemas identificados no processo de ensino-aprendizagem;

4. incentivar escolas públicas de Educação Básica, mobilizando seus professores como coformadores dos futuros docentes e tornando-as protagonistas nos processos de formação inicial para o magistério;

5. contribuir para a articulação entre teoria e prática necessárias à formação dos docentes, elevando a qualidade das ações acadêmicas nos cursos de licenciatura (UFES - PROGRAD, 2020) $)^{3}$.

Conforme se lê acima e dialogando com nossas experiências, acreditamos que o Pibid pode em muito contribuir para a valorização do magistério e para a formação docente por (re)inserir no contexto escolar graduandos cursando ainda a primeira metade de seu curso, já que muitos dos alunos bolsistas deixaram 'recentemente' a escola pública enquanto alunos dela. Assim, ao se distanciarem do lugar de aluno e se perceberem enquanto o outro que ensina e que educa, ou enquanto mestres e mediadores da aprendizagem que ocorre na sala de aula, é notória a transformação identitária na qual se engajam. Apoiadas em Hall (2011), entendemos o sujeito como sendo construído num processo dialógico entre sua participação social e as estruturas que sustentam suas interações com o meio e a sociedade em que o mesmo está inserido, processo esse marcado pela subjetividade, que, por sua vez, imprimirá marcas na sua construção identitária. O Pibid, portanto, se apresenta como elemento/estrutura fundante na construção identitária dos sujeitos participantes de suas dinâmicas uma vez que suas ações são constantemente negociadas e constituídas por meio do diálogo e dos sentidos que emergem de suas interações.

Assim, para além da iniciação em técnicas, metodologias, fazeres cotidianos e práticas docentes mais ou menos inovadoras, o Pibid se constitui enquanto arena de conflitos e contradições que emergiram a partir das interações que nele se dão e que precisaram ser encarados e ressignificados pelo Núcleo de Inglês da Ufes. Ademais, entendemos que a

3 Texto retirado da página oficial do Pibid Ufes da Ufes/Prograd, disponível em http://www.prograd.ufes.br/programa-institucional-de-bolsa-de-iniciacao-docencia-pibid. Acessado em 21/03/2020. 
emergência de tais conflitos nessa fase de sua formação, ou seja, ainda na primeira metade do curso, pode auxiliar nossos alunos graduandos a construir saberes e ideais mais compatíveis com a enorme complexidade do ambiente escolar público, construindo, assim, suas próprias identidades enquanto futuros professores de inglês nesse lócus. Ou seja, graduandos não precisam mais esperar pelo momento de seus estágios supervisionados curriculares, que geralmente acontecem no último ano de sua formação, para vivenciarem a docência e se identificarem (ou não) com ela. E disso também nos fala Hall (2012) quando pondera que a formação das identidades se dá, muitas vezes, por processos de (des)identificação com o outro, podendo portanto, o sujeito se assemelhar e se aproximar daquilo que o outro é, formando um todo "aparentemente" homogêneo, mas também podendo se definir pelo que não é diante do outro, ou, por aquilo que não deseja ser, mas que o escapa e que pode colocá-lo em lugar de conflito e contradição, no lugar da diferença. Diferença produzida pela linguagem, por discursos e subjetividades sobre os quais trataremos nas linhas que seguem.

Um dos maiores conflitos com os quais tivemos que lidar enquanto núcleo (ou talvez o maior deles!) se originou do distanciamento epistemológico entre o discurso e as ideias presentes nas salas de aula da graduação e nos encontros de formação do Pibid relacionadas à Educação Crítica de Línguas, e aquelas que pareciam fundamentar as práticas dos supervisores que acolheram os bolsistas de Inglês em 3 diferentes escolas da Grande Vitória (uma no município de Vila Velha e duas no município de Vitória). Durante o edital 2018-2019, os bolsistas tiveram oportunidades de observar aulas e interagir com alunos e supervisores de variadas maneiras e, como forma de registro de suas primeiras experiências, diários de campo (DC) semanais eram escritos e compartilhados com as coordenadoras. Nesses registros ${ }^{4}$ encontramos relatos bastante positivos, descrevendo situações em que os supervisores pediam ajuda para lançamento de notas, correção de atividades, monitoramento de atividades em sala, auxílio a alunos com dificuldades, conversas com professores de outras áreas na sala dos professores, acolhida dos profissionais da escola, dentre outros. Abaixo seguem alguns exemplos característicos do diálogo presente nas vivências do Pibid, e portanto, na constituição identitária dos graduandos por meio da identificação dos mesmos com o fazer docente:

\footnotetext{
${ }^{4}$ Todos os trechos aqui citados, oriundos dos diários de campo, foram transcritos ipsis litteris para não modificar os registros originais.
} 
[...] Enquanto o professor e o novo pibidiano foram para a sala de aula, eu e os outros pibidianos ficamos corrigindo algumas provas das turmas dele. Confesso que eu gosto bastante de corrigir provas, pois eu acho interessante a sensação de que eu estou fazendo algo que um professor de verdade faz (DC Álvaro, 19/10/2018) .

Particularmente eu achei interessante essa experiência de ver de perto como é uma reunião de pais, principalmente com um olhar agora de professor, e não de um aluno, pois isso tudo envolve uma série de questões que o professor sempre precisa estar atento em sala de aula (DC Álvaro, 13/09/2018).

Nesta terceira aula, como é uma aula de $\mathrm{PL}^{6}$, nós fomos para a sala dos professores. Lá, o supervisor nos chamou para conversar e nos propôs fazer o planejamento e dar uma aula pro terceiro ano voltado para alguma vertente que envolva o ENEM (inclusive nos deu uma ótima sugestão de aula cuja já estamos trabalhando para aplicar). Eu fiquei muito contente quando ele nos propôs isso e mais ainda quando ele me elogiou pela aula e por ter presença de fala em sala de aula (DC Hélio, 26/09/2018).

Eu saí da sala de aula realizado. Tive uma satisfação imensa ao ver meu trabalho sendo valorizado pelos alunos, ao ver aqueles alunos "do fundão" fazendo a atividade com seriedade, e ao ver que os alunos aprenderam algo do que nós havíamos planejado. Me senti um verdadeiro professor (DC Hélio, 10/10/2018).

Não obstante e, com o passar do tempo, relatos menos "empolgados" também surgiam, denunciando, talvez, uma possível vontade dos bolsistas de agirem em novas "frentes de trabalho", assumindo maior autonomia e extrapolando a comum (e para alguns "entediante") tarefa de observação e registro das aulas e das dinâmicas da sala de aula. Alguns desses relatos apontavam para práticas de ensinar e aprender marcadamente hierárquicas, nas quais aprendizes eram constantemente submetidos a lições passadas no quadro e copiadas nos cadernos para posterior avaliação por parte dos professores. A exemplo disso, seguem alguns relatos:

O professor passou um novo exercício no quadro, e antes de deixar que os alunos tentassem responder sozinhos, trabalhou com toda a turma a tradução das frases, para facilitar a compreensão (DC Carla, 11/09/2018).

Neste dia o professor já iniciou o novo conteúdo referente ao terceiro trimestre, Present Perfect Continuous. No quadro, escreveu as regras, exemplos e exercícios para praticarem. O professor explicou usando mais exemplos do que os que estavam escritos no quadro, acrescentando exemplos pessoais para explicar as regras (DC Carla, 21/08/2018).

P [o professor] copiou a matéria no quadro e, assim como em todas as suas aulas (é quase uma rotina), ele deu vistos e fez a chamada. Durante esse momento eu divaguei sobre o fato de que mesmo estando na posição de "professor em treinamento" e as outras pessoas naquela sala em posição de "alunos do ensino médio", muitos dos estudantes ali tem a mesma idade que eu ou são até mais velhos. Achei curioso esse ponto e notei que eles nem sequer deram conta disso ainda (DC, Hélio, 03/10/2018).

\footnotetext{
${ }^{5}$ Os verdadeiros nomes dos bolsistas autores dos registros aqui apresentados foram todos substituídos por questões de privacidade e para a preservação de suas identidades.

6 "Aula de PL" designa aqui a carga horária referente ao planejamento realizado pelos professores dentro da escola.
} 
O plano de aula foi o mesmo utilizado na turma anterior, então ele seguiu os mesmos passos: matéria no quadro - tempo para copiar - explicação (DC, Hélio, 05/09/2018).

Segundo muitos relatos nos diários, tais lições pouco dialogavam com o cotidiano dos alunos(as), uma vez que se pautavam em conteúdos sugeridos/exigidos pelo currículo em prática nas escolas participantes (em uma escola Ensino Fundamental e nas demais Ensino Médio) e, que, por sua vez, eram trabalhados de forma primariamente descontextualizada, por meio de frases e listas de palavras expostas no quadro. Nesse sentido, a crítica de Fortes (2018) ao ensino descontextualizado, comumente presente em práticas que acabam por construir e reforçar o discurso do fracasso do ensino de LI na escola pública, pode servir como pano de fundo para muitos dos conflitos epistemológicos entre a formação inicial de hoje e aquelas às quais os supervisores foram expostos e submetidos. Assim, enquanto nas aulas da graduação falávamos de pedagogias de letramentos, multiletramentos e letramento crítico, buscando enfatizar a noção de linguagem como discurso e prática social e distanciarmo-nos do entendimento de língua como estrutura fixa, homogênea e não-situada sociohistoricamente, as experiências narradas pelos bolsistas de Inglês desvelavam "práticas de ensino e de linguagem que fazem pouco sentido para aprendizes por se distanciarem de seus repertórios e de suas vivências cotidianas, ou, simplesmente porque alunos podem não conseguir lidar com tamanha abstração ou complexidade" (FORTES, 2018, p. 142). Disso já falavam Kalantzis e Cope (2012) quando criticavam a incapacidade da escola de se conectar com os cotidianos dos alunos, enfatizando o ensino de regras e conteúdos abstratos e distantes das experiências de linguagem que os sujeitos da escola vivenciam fora dela. Gee (2004) também se refere a tais abstrações, às quais ele classifica como "o buraco negro do jargão" da linguagem acadêmica.

Para além de noções de língua/linguagem, texto e discurso enviesados sociologicamente, o embate epistemológico também esbarrava na crítica à educação bancária que hoje se faz nas licenciaturas em geral, fortemente influenciadas e inspiradas pelo maior educador brasileiro, Paulo Freire. Enquanto buscamos desconstruir o modelo de ensino centrado na figura do professor, que, por sua vez, é visto como detentor do saber e, mais ainda, do saber válido, legítimo e tido como "relevante" e imprescindível à escolarização, por muitas vezes os bolsistas de LI do Pibid Ufes se mostravam incomodados com atitudes extremamente hierárquicas e autoritárias na sala de aula. No entanto, apesar das observadas hierarquias e da centralidade na figura do professor, muitos registros feitos nos diários e relatórios dos bolsistas 
apontavam para conflitos pautados na ausência de autoridade por parte dos professores supervisores em 'controlarem' suas turmas. Tais atitudes, notadamente presentes nas descrições do ambiente da sala de aula, se referiam a comportamentos alheios por parte dos alunos, falta de respeito à figura do professor, falta de engajamento com as tarefas propostas, etc., o que denunciava um contexto bastante similar àquele descrito em Fortes (2017) e em diversos outros trabalhos que acabam por reforçar a urgente necessidade por ressignificações acerca do ensino de inglês na escola pública e no ensino regular/básico. O relato abaixo é um exemplo disso, e também pode ser visto e analisado como possível influência na constituição identitária da bolsista que o narra quando a mesma se mostra desiludida ao se desidentificar com o que observa, ou seja, com aquilo que (ainda) não consegue transformar e que não almeja para seu futuro enquanto professora:

Durante a aula, observei muitos alunos do fundo jogando baralho e até mesmo jogando grampos de grampeador, inclusive dois foram parar em mim. Houve muita conversa, gritaria e cantoria. Sempre notei essa turma mais agitada do que a outra que vamos depois do intervalo ...Mas sinceramente não saberia como reagir a isso, estamos presenciando muito desrespeito aos professores, eles estão perdendo seu valor e vejo que o professor de inglês então eles não levam muito a sério. Utilizam as aulas de inglês pra fazerem qualquer coisa além do inglês e infelizmente o professor "tem que aceitar isso", senão pode ser ameaçado. Não sei se mudando o método de ensino iria levar a alguma coisa, ultimamente estou muito triste e pensando como mudar essa situação (DC Isadora 20/09/2018).

Importante ressaltar que, por muitas vezes, os professores supervisores estavam alinhados e empolgados com as teorias apresentadas pelas coordenadoras nos encontros de formação mensais. No entanto, justificavam a impossibilidade de se apropriarem das mesmas e de colocá-las em prática principalmente pelo excesso de carga horária docente que tinham. Ou seja, percebiam as teorias como relevantes para o contexto escolar em que atuavam, mas careciam de tempo para executá-las. Um dos supervisores, ao fim do programa, relatou que está aberto à implementação de novas práticas, mas entende ser "humanamente impossível apesar de concordar com as ideias e perspectivas" (Depoimento supervisor, 25/11/2019). Esse relato não denuncia o conflito epistemológico em si, mas sim conflitos de ordem estrutural (condições de trabalho) que podem prejudicar o trabalho docente por diversas outras razões.

Contudo, por mais que entendamos as condições precárias em que os professores de LI atuam, especialmente na educação pública, acreditamos que o Pibid possa, e deva, agenciar mudanças de atitude e promover novos discursos, ainda que os mesmos levem bastante do nosso tempo e consumam muito da nossa energia, ou ainda que levem tempo para se materializarem 
e traduzirem-se em práticas mais engajadoras e conectadas com o cotidiano e com a linguagem dos aprendizes da escola básica. Sobretudo, reiteramos o lugar do Pibid Inglês enquanto instância constituidora de identidades múltiplas (pela identificação e pela desidentificação), espaço de crises, conflitos e possíveis e desejáveis rupturas com a educação didática (KALANTZIS E COPE, 2008) ainda inserida no paradigma tradicional criticado por Lemke (2010) e em seus arranjos pouco preocupados em fazer com que a educação formal e a língua inglesa façam cada vez mais sentido para seus aprendizes, representando suas realidades e as práticas discursivas da atualidade, como sinalizado em Fortes (2018),

\begin{abstract}
Acredito que a partir do momento em que buscarmos, de fato, romper com o ensino descontextualizado e estruturalista tão característico das aulas de inglês na escola regular estaremos a promover a construção de uma sociedade mais justa e a construir identidades mais condizentes com os desafios da contemporaneidade. Estaremos também desconstruindo o Discurso do Fracasso do ensino de inglês na escola pública, ressignificando e reafirmando, assim, a sua grande relevância para a educação formal e para a formação humana (FORTES, 2018, p. 149-150).
\end{abstract}

\title{
Expansões, rupturas, ressignificações
}

Mas por que a ruptura com o paradigma tradicional parece ser tão difícil para nós, professores? É preciso lembrar que somos sujeitos constituídos sócio historicamente, ou seja, somos formados por diversos discursos que circulam em nosso entorno (GEE, 2012). Se pensarmos que o paradigma convencional de educação parece ainda ser o predominante em nossa sociedade e, portanto, nas escolas e nos cursos de formação de professores, fica fácil imaginar o porquê de, muitas vezes, ficarmos/sermos resistentes às rupturas e, por sua vez, a mudanças. Além disso, há de se considerar que os discursos acadêmicos mudam com o passar dos anos e das gerações, o que, por si só, já justificaria a existência de conflitos epistemológicos entre currículos e projetos pedagógicos de cursos (PPCs) por um lado, e por outro, os docentes na ativa participantes do Pibid em 2018-2019, formados há cerca de 10 anos, pelo menos.

Soma-se a isso o fato de que os cursos de formação de professores muitas vezes deixam a desejar no que tange às reflexões acerca das epistemologias e filosofias educacionais, focando predominantemente nas práticas docentes (MONTE MOR, 2011), ou ainda, deslocando a teoria da prática ao invés de enfatizar a dimensão da práxis ou das razões pelas quais certas práticas são como são. Sim, pensar nas práticas e nos contextos de aplicação é de extrema importância, 
mas sem a devida reflexão sobre os motivos que nos levam àquelas práticas, não alcançaremos a desejada "reforma do pensamento", da qual fala Morin (2011, p. 20), dificultando a também necessária reforma do ensino. Vale lembrar que não se trata aqui de uma busca por um paradigma ou por uma epistemologia ideal; defendemos a pluralidade de epistemologias, entendendo-as como as diversas formas de construir conhecimento na sociedade (SOUSA SANTOS, 2010).

Em Oliveira (2017), podemos encontrar uma problematização das características do conhecimento construído no paradigma da Modernidade e suas consequências para a formação de professores e para a escolarização. A autora apresenta a metáfora arborescente que, segundo Gallo (1995), é a representação associada à construção de conhecimento da Modernidade que ainda prevalece em nossa sociedade. A partir dela, os conhecimentos são construídos de forma hierárquica, unidirecional e fragmentada. Hierárquica quando os diversos saberes, os galhos, são provenientes de um saber mais estruturado, o tronco, que promove outros conhecimentos em etapas de crescimento, do mais amplo ao mais específico. Unidirecional quando todos os saberes originam-se de uma fonte segura, o tronco, o conhecimento científico. Fragmentada quando os galhos vão se ramificando, mas ainda permanecem no seu galho maior. Assim, as diversas áreas do saber não interagem; cada galho vai se tornando maior, mais especializado, mais específico em seu próprio meio.

Além das três características descritas acima, o conhecimento da era moderna, em decorrência da busca pela razão objetiva, acabou por criar dicotomias, binarismos que, por sua vez, "impedem o imprevisto, o não-padrão, a alteridade" (OLIVEIRA, 2017, p. 34), o que nos leva a compreender as dicotomias presentes na formação e na prática dos professores. Talvez a mais conflituosa seja a separação entre teoria e prática, que tanto prejudica os processos de ensinar e aprender e a própria relação entre a Universidade e a Educação Básica. É preciso, portanto, entender que essas duas dimensões são inseparáveis e não dicotômicas.

Outra dicotomia herdada da racionalidade da Modernidade é a separação entre sujeito e objeto de estudo nas pesquisas científicas, essas privilegiando as Ciências Naturais em detrimento das Ciências Humanas. Tal dicotomia acabou por objetificar e quantificar o conhecimento, privilegiando o método científico, legitimando apenas o conhecimento que pode ser provado e testado pelo mesmo. Desta forma, "o conhecimento torna-se a verdade que o método produz e valida" (OLIVEIRA, 2017, p. 32) e, por sua vez, o que não pode ser objetificado (REAGAN, 2009) é desprezado e não considerado um conhecimento legitimado. 
Ou seja, os conhecimentos das Ciências Humanas eram descartados por serem muito subjetivos. Nas palavras de Nicolescu (1999), “todo conhecimento, além do científico, foi afastado para o inferno da subjetividade, tolerado no máximo como ornamento, ou rejeitado com desprezo como fantasma, ilusão, regressão, produto da imaginação” (NICOLESCU, 1999, p. 18).

Essas dicotomias nos levam à ideia de que vivemos de um lado ou de outro, ou do certo ou do errado, mas nunca 'entre', o que nos leva a imaginar que temos identidades fixas e, portanto, estamos na esfera do estável, do imutável. Desta forma, acabamos por nos separar entre linhas radicais: o universo deste 'lado da linha' e o universo 'do outro lado da linha', eu e o outro, nós e eles (SOUSA SANTOS, 2010, p. 32). Sousa Santos (2010) define o pensamento ocidental moderno como o pensamento abissal, aquele que considera "as margens como realidades não existentes" (SOUSA SANTOS, 2010, p. 32). A copresença dos dois lados da linha é impossível nesse tipo de pensamento. Desta forma, "o pensamento abissal moderno salienta-se pela sua capacidade de produzir e radicalizar distinções" (SOUSA SANTOS, 2010 p. 33); distinções entre o conhecimento legitimado pela ciência (de um lado) e tantos outros conhecimentos não legitimados, já que não obedecem aos critérios científicos estabelecidos. Como consequência, temos as portas fechadas para o que Sousa Santos (2010) chama de 'ecologia dos saberes' que, justamente, pressupõe a existência de múltiplos saberes, legitimando aqueles que estão 'do outro lado da linha'. Acreditamos numa prática fundamentada nessa perspectiva.

Durante o processo de formação do Pibid Inglês Ufes percebemos a tal concepção Moderna de conhecimento (língua desconectada de práticas sociais; visão estruturalista de língua; hierarquia marcada nas interações de sala de aula; foco excessivo em avaliações) enraizada na prática dos professores que, por sua vez, também é decorrente de um sistema educacional que parece não contribuir para uma quebra de paradigma que possa romper com valores e práticas ainda bastante tradicionais, rígidas e controladoras. No que diz respeito ao sistema educacional, este parece sobrecarregar os professores de tarefas e relatórios que acabam tomando tempo precioso que poderia ser despendido com formação e planejamento de aulas. Outra questão observada ao longo do Projeto é em relação à quantidade de provas que os professores elaboraram para oferecer as muitas recuperações (chances) às quais os alunos têm direito numa tentativa de evitar reprovações; bem como os inúmeros vistos dados nos cadernos dos alunos, também como forma de avaliá-los, conforme se lê nos relatos abaixo. 
Percebe-se então, no Pibid Inglês, uma prática docente que parece valorizar a mensuração do conhecimento da qual nos fala Biesta (2010), ou seja, apenas o que pode ser medido e avaliado é levado em consideração. Rotinas tais como vistos no caderno e grande quantidade de provas e exercícios para nota são um indício disso, especialmente se pensarmos que nos contextos em voga havia uma ou duas aulas de inglês por semana, sabendo-se ainda que muitas vezes as aulas de inglês eram/são canceladas ou substituídas por tarefas e eventos que fogem do controle e do planejamento do professor. Essas práticas avaliativas acabam por priorizar a construção de uma identidade única e "aparentemente estável", em detrimento da pluralidade de sujeitos e de formas de aprendizagem presentes na complexidade em que vivemos, já que padronizam, disciplinam/controlam, punem e buscam sempre a convergência de opiniões por meio de respostas "corretas". Apresentamos alguns relatos escritos pelos graduandos bolsistas no intuito de exemplificar nossos argumentos:

Após o professor chegar ele explicou como seria a aula, e começou a passar uma atividade no quadro. Tal atividade valia um ponto extra, e isso me chamou atenção pelo fato de que: os alunos recebem carimbos em tudo que copiam do quadro, valendo dez pontos, sendo que eles sempre podem trazer uma segunda vez os cadernos quando estes não estão completos, uma fazem uma prova valendo dez pontos, e têm um trabalho valendo dez pontos. Ainda assim, o professor dá mais pontos extras para que eles não fiquem com notas baixas. Eu sinceramente acho que um dos motivos para a desvalorização da aula de inglês é justamente o fato de que com tantos pontos dados de maneiras "fáceis demais" fica fácil passar na matéria, e consequentemente os alunos nem ao menos se esforçam para realmente aprender algo (DC Hélio, 31/10/2018).

Na sala do terceiro ano, a prova já havia ocorrido, então era dia de correção de provas, o professor estava fazendo chamada e eu estava com bastante tédio, então pedi a ele para que eu pudesse entregar as provas para que eu tivesse algo para fazer, ele felizmente me permitiu e entreguei-as aos alunos, as notas foram bastante razoáveis, alguns alunos com notas muito boas e outros com notas bem baixas, o professor então começou a correção da prova, houve bastante bagunça mas ele conseguiu controlar bem a confusão, corrigiu a prova e logo acabou essa aula também. (DC, Leandro, 20/08/2018).

No último horário foi novamente prova, não tive nada para fazer novamente mas observei que nessa sala havia alunos colando, o professor também viu mas não se importou, então às $17 \mathrm{~h}$ saí de lá (DC Leandro, 20/08/2018).

Por outro lado, durante as correções das provas, percebi que infelizmente os alunos não compreenderam muito sobre a disciplina. Isso acontece porque geralmente o professor trabalha apenas tradução e os tempos verbais isoladamente e sem contexto (mesmo tendo o livro com muitos temas interessantes) apenas a gramática por si só. E quando chega na hora da prova ele pede para fazer compreensão de texto. O resultado disso é muitas notas baixas, e consequentemente o professor acaba criando outras atividades para que eles possam recuperar a nota e passar de ano. (DC Lorena, 21/11/2018).

No último trecho destacado acima, vê-se como a questão do ensino descontextualizado gera consequências também para as práticas avaliativas quando se mostram desalinhadas com propostas de uso da LI mais contextualizadas e representativas, o que entendemos como práticas sociais de uso da língua, no caso do excerto, a leitura de um texto. Tal dissonância entre práticas 
de sala de aula e rotinas avaliativas acabam por gerar a necessidade de se pensar em novas formas de avaliação para que alunos tenham suas notas "recuperadas" e possam "passar de ano".

Ainda sobre as práticas dos professores, percebemos, muitas vezes, uma postura hierárquica, tendo a imagem da figura do professor como (o único?) detentor do conhecimento, aquele que é o dono da verdade absoluta ou ainda aquele que provê as respostas aos alunos antes mesmo de dar-lhes a oportunidade de respondê-las. Esta "verdade" pode ainda se manifestar por meio do ensino estruturalista da língua inglesa, conforme pontuado acima em muitos dos registros supracitados, com exercícios gramaticais e listas de vocabulário expostos no quadro e muitas vezes descontextualizados, o que nos remete ao tecnicismo, cientificismo e objetificação do conhecimento da Modernidade e, portanto, da língua. Vemos prevalecer o paradigma reducionista que não leva em consideração as práticas sociais de linguagem e os contextos mais amplos nos quais as estruturas acontecem, ao contrário do que defende Morin (2011) quando discorre sobre a complexidade na qual os sujeitos estão inseridos, não escapando, portanto, a linguagem. Como ele mesmo diz, somos ensinados desde pequenos a

isolar os objetos (de seu meio ambiente), a separar as disciplinas (em vez de reconhecer suas correlações), a dissociar os problemas, em vez de reunir e integrar. Obrigam-nos a reduzir o complexo ao simples, isto é, a separar o que está ligado; a decompor, e não a recompor; e a eliminar tudo que causa desordens ou contradições em nosso entendimento (MORIN, 2011, p. 15).

Nós, professores, também fomos (e/ou ainda somos) ensinados desta forma. No entanto, acreditamos que o professor de línguas estrangeiras, e no nosso caso mais específico de LI, possui uma especificidade ou até mesmo uma vantagem: estamos acostumados a trabalhar de forma interdisciplinar junto a outras áreas de conhecimento, o que pode/poderia tornar mais provável alguma mudança epistemológica. Moita Lopes (2002) já nos dizia que a sala de aula de língua inglesa é campo fértil para a pluralidade de ideias uma vez que há a constante presença do Outro: outra cultura, língua e identidade. Precisamos aproveitar essa oportunidade, não?

No que tange ao ensino com foco na gramática, vale ressaltar que uma das críticas às teorias dos letramentos feitas pelos supervisores foi justamente a ausência, observada por eles, do ensino das estruturas gramaticais. Um dos supervisores relata que "a gramática acaba não acontecendo; fica só no conteúdo emancipatório" (Depoimento supervisor, 25/11/2019). Esta é uma crítica comum aos estudos dos letramentos que, a nosso ver, faz parte da mudança epistemológica ou reforma do pensamento que estamos defendendo aqui. Não se trata de 
eliminar o ensino da gramática, mas sim torná-la parte dos textos, contextos e práticas sociais nas quais os alunos estão inseridos. Vemos aqui mais um resquício dicotômico da Modernidade: sujeito e contexto separados, língua separada de identidade, sem a consciência de que sujeito e linguagem são constituídos sócio historicamente. No ensino não seria diferente, em especial, no ensino de línguas.

No entanto, gostaríamos de destacar que esses conflitos epistemológicos, observados pelas coordenadoras do Projeto nos encontros de formação com os bolsistas e supervisores e por meio das leituras dos diários de campo dos bolsistas, foram tratados com todos os envolvidos no processo de formação do Pibid de maneira dialogada e compreensiva, contribuindo para um enriquecimento formativo único tanto para a Educação Básica quanto para a Universidade. Afinal, como diria Todd (2009), a educação não deve evitar o conflito, mas sim lidar com o mesmo. Nas linhas que seguem, debateremos um pouco mais sobre a natureza conflituosa das experiências do Pibid Inglês Ufes e de como as mesmas dialogam com os propósitos da subjetificação e da emancipação.

\section{A beleza da formação pelo conflito: emancipação e subjetificação}

Para Biesta (2013), o processo educacional envolve riscos e fraquezas mas, ao contrário do que se possa pensar desses dois termos, o filósofo entende que sem estes, a educação perde sua razão de ser. São estes que a tornarão um processo subjetificador e emancipatório; subjetificador porque insere algo novo e único no mundo, imprevisto ou nunca feito exatamente 'daquela' maneira, ou ainda, porque valoriza a pluralidade de formas de ser e de pensar, permitindo a crítica e a desidentificação com discursos e funcionamentos já estabelecidos. Ou seja, uma educação subjetificadora promove a formação de identidades menos estáveis, múltiplas, não convergentes, críticas e questionadoras. Assim, inspirado em Rancière, Biesta (2013) afirma que a dimensão subjetificadora da educação é a própria emancipação. Nessa dinâmica entre aceitação e não aceitação, identificação e desidentificação, cumplicidade e crítica, nos constituímos enquanto seres únicos capazes de fazermos escolhas e transformarmonos ao mesmo tempo em que temos a chance de transformar o mundo e o estado de coisas à

nossa volta. É, portanto, por meio dos conflitos inerentes ao processo educacional que encontraremos a beleza do mesmo. 
Ademais, não estamos a defender que visões e práticas educacionais distintas se excluam binária e mutuamente ou se anulem, mas que possamos estabelecer uma relação dialética entre a emancipação e as estruturas socioculturais já existentes, de maneira que a agência seja pautada pelas subjetividades daqueles envolvidos no processo educacional e por reflexões críticas acerca das estruturas ali presentes. Assim, a lógica emancipatória que defendemos se baseia na ideia de que ninguém emancipa ninguém, e que é preciso desierarquizar a sala de aula e a formação docente se almejamos qualquer tipo de educação libertadora (FREIRE, 1987). A partir de uma consciência crítica pautada em valores éticos e na indissociação entre teoria e prática, educadores e educandos se emancipam passando a agir no mundo de forma protagonista e ativa, conforme se lê abaixo:

\begin{abstract}
Desta maneira, o educador já não é o que apenas educa, mas o que, enquanto educa, é educado, em diálogo com o educando que, ao ser educado, também educa. Ambos, assim, se tornam sujeitos do processo em que crescem juntos e em que os "argumentos de autoridade" já não valem. Em que, para ser-se, funcionalmente, autoridade, se necessita de estar sendo com as liberdades e não contra elas (FREIRE, 1987, p. 68).
\end{abstract}

É preciso dizer que, ao coordenar o Pibid Inglês pela primeira vez, nós aceitamos o risco do desconhecido e sabíamos que conflitos epistemológicos poderiam e deveriam acontecer, denunciando o fato de que, enquanto educadoras estávamos também em processo. Assim, éramos chamadas a agir em situações por nós nunca vivenciadas, ainda que tivéssemos que respeitar a autonomia e a história de cada supervisor e bolsista ali envolvido, estando junto, sem impor nossas visões, por mais que acreditássemos nelas. Nesse mesmo barco também estavam os supervisores pois, ainda que fossem vistos como mestres e 'modelos', uma vez que eram observados e responsáveis pelos bolsistas e pelas tarefas que deveriam realizar, tinham que lidar com as novidades epistemológicas e com o desconhecido que a interação com a academia lhes proporcionava. Por fim, alguns bolsistas graduandos ansiosos e desejosos por assumirem lugares mais protagonistas enquanto educadores em formação acabavam esbarrando na autoridade do supervisor que, por vezes, não se abria ao novo e ao risco ou que, por razões burocráticas, não conseguia abrir mão de seus planejamentos e conteúdos, impedindo assim que a subjetividade desses pibidianos emergisse por meio de suas ações docentes, das atividades que planejavam e das rupturas e desconstruções que desejavam causar.

As vivências que adquirimos pelo Pibid nos mostram que a ideia de emancipação como ponto de chegada foi e sempre será bastante conflituosa e arriscada, mas, que, nem por isso devemos desistir dela se desejarmos, de fato, trilhar caminhos outros para a educação crítica de língua inglesa e a sua formação de professores. Por muitas vezes precisávamos "acalmar os 
(des)ânimos" de muitos bolsistas que se indignavam com a impossibilidade de agirem de forma protagonista e transformadora. Nem todos os bolsistas se mostravam desanimados, é claro, mas, devemos admitir que, se estamos a falar de conflitos nessa escrita bastante narrativa e reflexiva, devemos isso à própria subjetificação que vimos acontecer. Nesse sentido, Rancière pontua que "[a] igualdade jamais vem após, como resultado a ser atingido. Ela deve sempre ser colocada antes" (RANCIÈRE, 2011, p. 11), ou seja, qualquer "ignorante" detém saberes que não podem ser esquecidos, e a esse esquecimento Rancière denomina "embrutecimento".

A universidade muitas vezes possui uma postura 'embrutecida' em relação ao que deve ser ensinado/abordado na escola pública. Chegamos à escola desejando propor novos sentidos para a sala de aula contemporânea não com o intuito de impor nossas visões, mas, sim, com o desejo de dialogar com os professores sobre mais uma perspectiva para o ensino de línguas estrangeiras, o que Monte Mór chamaria de "um passo a mais" (MONTE MÓR, 2018). Estávamos nós, e nossos bolsistas "embrutecendo" ao fazer e querer isso?

Acreditamos, com Jordão (2016), na escola como um espaço habitado por seres inteligentes, que trazem consigo conhecimentos de ordens diversas que, quando compartilhados, "constroem o mundo como um espaço de agência criativa e transformadora" (JORDÃO, 2016, p. 43). Entendemos que o ensino de inglês na escola básica deve cumprir com seu papel de 'qualificar' sujeitos pelo ensino de conteúdos, inseri-los em arranjos sociais e, acima de tudo, transformá-los identitariamente, transcendendo os limites da escola para a vida social pelo respeito às diferenças e à subjetividade. Assim, remetendo ao argumento de Rancière (1991), o professor também reconhece seu aluno como igual e capaz, reforçando a ideia de que visões de mundo binárias desfavorecem o trabalho e a aceitação das diferenças (e portanto, da subjetividade), especialmente porque categorizam o mundo e são naturalmente aceitas sem que sujeitos exerçam sua agência nele pela desconstrução de tais formações discursivas, pela desidentificação, pelo embate e a crítica a elas.

\section{Considerações finais}

O Pibid Inglês da Ufes 2018-2019 foi bem isso: um processo de formação de professores subjetificador, complexo, conflituoso, belo. Processo pelo qual participantes experienciaram oportunidades de aprender, se abrir ao novo, ao risco, ainda que para alguns sujeitos a mudança tenha sido mais ou menos possível, complexa e necessária. O 'aprender fazendo' 
(LANKSHEAR e KNOBEL, 2003) esteve presente a todo momento, o que nos (todos os envolvidos) fazia parar para ver, rever e refazer nosso planejamento e tomada de decisões. Processo... em processo... inacabado... imperfeito... em formação...

Entendemos que a percepção sobre a relevância dos propósitos de uma educação crítica leva tempo e que a emancipação do pensamento e da práxis docente é também relativa a estruturas de um sistema que, aparentemente, não favorece a transformação, e que, ainda pode influenciar "negativamente" as identidades dos sujeitos da escola pública ao os colocarem em situação de estresse e exclusão. Os alunos/bolsistas graduandos nos mostraram que, ao se desidentificarem com aquilo que viam, acabaram se permitindo "vir ao mundo" de maneiras próprias e únicas, distanciando-se do modelo que presenciaram e com o qual interagiram. Isso já nos fortalece e nos enche de esperança.

Já nós, formadoras em (trans)formação, aceitamos o risco e a imprevisibilidade como caminhos possíveis e engrenagens para novas formas de ser e educar. Sabemos das inúmeras barreiras, e buscaremos, por meio de diálogos cada vez mais abertos, reconstruir nossas identidades por meio de uma práxis docente ética e responsável. Assim, a pergunta a nós feita por Morin (2011), 'Quem educa os educadores?' ganhou uma resposta aqui: os participantes envolvidos no processo de formação. E isso só foi possível porque trabalhamos na coletividade, na pluralidade, as quais, como nos ensina Arendt (2014), são a condição para a existência e a ação humana. Se queremos uma educação transformadora, talvez esse seja um dos possíveis caminhos.

E assim tentamos realizar um trabalho integrador entre a Universidade e a Educação Básica, objetivo central do Programa Pibid, superando a dicotomia entre teoria e prática, contribuindo, talvez, para uma construção menos hierárquica e 'embrutecida' do conhecimento. Buscaremos, certamente, outras parcerias.

\section{Referências bibliográficas}

ARENDT, H. A condição Humana. Chicago, Illinois: The University of Chicago Press. 1958 ( $1^{\text {a }}$. Ed.) Tradução: Roberto Raposo, revisão: Adriano Correia. Rio de Janeiro: Forense Universitária. 2014.

BIESTA, G. J. J. Good Education in an Age of Measurement: ethics, politics, democracy. London: Paradigm Publishers, 2010. 
The Beautiful Risk of Education. London: Paradigm Publishers, 2013.

DELEUZE, G.; GUATTARI, F. Mil Platôs: capitalismo e esquizofrenia. São Paulo: Editora 34, 1995.

FORTES, L. "Ser ou não ser": questões sobre subjetividade e o ensino de inglês na escola pública. 2017. 233f. Tese (Doutorado em Estudos Linguísticos e Literários em Inglês) Faculdade de Filosofia, Letras e Ciências Humanas, Universidade de São Paulo, São Paulo, 2017.

Ressignificando o ensino (descontextualizado) de língua inglesa na escola pública: letramentos, engajamento e subjetificação. PERcursos Linguísticos, Vitória, v. 8, n. 20, p. 132 $152,2018$.

FREIRE, P. Pedagogia do Oprimido. (17a. Ed.) Rio de janeiro, RJ: Paz e Terra, 1987.

GALLO, S. Conhecimento, transversalidade e currículo. In: XVIII REUNIÃO ANUAL DA ANPED. 18, 1995, Caxambu. Mimeo. Caxambu, 1995b, s/n. Disponível em: <http://www.ia.ufrrj.br/ppgea/conteudo/T2-4SF/Akiko/13-Transversalidade.doc> Acesso em:

GEE, J. P. Situated Language and Learning. New York \& London, Routledge, 2004.

Social Linguistics and Literacies: Ideologies in Discourses. (4 ${ }^{\mathrm{a}}$. Edição). London, UK: Routledge. 2012.

HALL, S. A identidade cultural na Pós-Modernidade (11ª Ed.). Rio de Janeiro: DP\&A Editora. 2011.

Quem precisa de identidade? In: SILVA, T. T. (Org.) Identidade e Diferença: a perspectiva dos estudos culturais. 12a . edição. Petrópolis, RJ: Vozes. 2012.

JORDÃO, C. M. No tabuleiro da professora tem... Letramento Crítico? In: JESUS, D. M.; CARBORIERI, D. (Orgs.) Práticas de Multiletramentos e Letramento Crítico: Outros sentidos para a Sala de Aula de Línguas. Campinas SP: Pontes Editores. 2016.

KALANTZIS, M. \& COPE, B. New Learning: elements of a science of education. (2nd Ed). NY: CUP. 2008.

. Literacies. NY: Cambrigde University Press. 2012.

LANKSHEAR, C.; KNOBEL, M. New Literacies: Changing knowledge and Classroom Learning. UK: Open University Press. 2003. 2007.

LEMKE, J. Letramento Metamidiático: transformando significados em mídias. In: Trab. Ling. Aplic., Campinas, 49(2): 455-479, Jul./Dez. 2010

MONTE MÓR, W. Critical literacies in the Brazilian university and in the elementary/secondary schools: the dialectics between the global and the local. In: MACIEL, R. F. E; ARAUJO, V. A. (Org.) Formação de Professores de Línguas: ampliando perspectivas. Jundiaí: Paco Editorial, 2011. 
MORIN. E. A cabeça bem-feita: repensar a reforma, reformar o pensamento. Rio de janeiro: Bertrand Brasil, 2011.

NICOLESCU, B. O Manifesto da transdisciplinaridade. São Paulo: TRIOM, 1999.

OLIVEIRA, L. F. Epistemologias educacionais emergentes: um olhar crítico. Tese (Doutorado), USP, São Paulo, 2017.

RANCIÈRE, J. O Mestre Ignorante - cinco lições sobre a emancipação intelectual. (Tradução de Lilian do Valle). $3^{a}$. Edição. Belo Horizonte: Editora Autêntica. 2011.

REAGAN, T. Objectification, positivism and language studies: a reconsideration. Critical Inquiry in Language Studies. London: Taylor \& Francis, 2004.

SOUSA SANTOS, B. Para além do pensamento abissal: das linhas globais a uma ecologia de saberes. In: SANTOS, B. S.; MENESES, M. P. (Orgs.) Epistemologias do Sul. São Paulo: Cortez, 2010, p. 31-83.

TODD, S. Toward an Imperfect Education: facing humanity, rethinking cosmopolitanism. London: Paradigm Publishers, 2009. 